\title{
O PROFESSOR AMARO CAVALCANTI E A IMPRENSA DO CEARÁ: UMA LEITURA DO INTELECTUAL NO IMPÉRIO BRASILEIRO ${ }^{12}$
}

\author{
Fabiana Sena ${ }^{3}$
}

\section{RESUMO}

Este estudo tem como objetivo analisar o processo de construção da figura de Amaro Cavalcanti, professor de Latim e advogado provisionado, na cidade de Baturité, como intelectual no final do século XIX, por meio de suas ações e discursos sobre ele publicados na imprensa do Ceará, mais especificamente no periódico Cearense. Para esse propósito, buscamos identificar o seu relatório sobre o sistema de ensino dos Estados Unidos da América e da proposta de reforma para a província do Ceará, as mudanças de funções e cargos altos na cena pública. Identificar o itinerário de Amaro Cavalcanti nos periódicos possibilita compreender a sua rede de sociabilidade e suas ações no campo da instrução, de modo que a imprensa se configura como um instrumento de construção e legitimação do intelectual e, ao mesmo tempo, meio de divulgação do fenômeno da

\footnotetext{
${ }_{1}^{1}$ Parte deste estudo foi apresentada em uma mesa-coordenada no VIII Congresso Brasileiro de História da Educação (CBHE) de Maringá/PR, de 29 de junho a 2 de julho de 2015.

${ }^{2}$ Teve apoio do Pibic/CNPq.

3 Universidade Federal da Paraíba (UFPB), João Pessoa/PB, Brasil.
} 
instrução pública na província do Ceará.

Palavras-chave: intelectual, instrução, imprensa, Império.

\title{
EL PROFESOR AMARO CAVALCANTI Y UNA PRENSA DEL CEARÁ: UNA LECTURA DEL INTELECTUAL EN EL IMPERIO BRASILEÑO
}

\section{RESUMEN}

Este estudio tiene como objetivo analizar el proceso de construcción de la figura de Amaro Cavalcanti, profesor de Latín y abogado provisto, en la ciudad de Baturité, como intelectual a finales del siglo XIX, por medio de sus acciones y discursos sobre él publicados en la prensa de Ceará, más específicamente en el periódico Cearense. Para obtener el mayor objetivo de búsqueda, mayor número de informes sobre el sistema educativo de los Estados Unidos de América y la propuesta de reforma para Ceará, como cambios de funciones y cargas más altas en la escena pública. Identificar el itinerario de Amaro Cavalcanti en los periódicos puede comprender su red de sociabilidad y sus acciones en el campo de la instrucción, de modo que la prensa se configura como un instrumento de construcción y legitimación del intelectual y, al mismo tiempo, medio de divulgación del fenómeno de la instrucción pública en la provincia de Ceará.

Palabras clave: intelectual, instrucción, prensa, Imperio.

\section{THE TEACHER AMARO CAVALCANTI AND A CEARÁ PRESS: A READING OF THE INTELLECTUAL IN THE BRAZILIAN EMPIRE}

\begin{abstract}
This study aims to analyze the process of construction of the figure of Amaro Cavalcanti, a Latin teacher and lawyer provisioned in the city of Baturité, as an intellectual at the end of the 19th century, through his actions and speeches published in the press of Ceará, more specifically in the periodical Cearense. To obtain the largest search goal, more reports on the education system of the United States of America and the proposed reform for Ceará, such as changes of functions and higher loads on the public scene. Identifying the itinerary of Amaro Cavalcanti in the periodicals can understand his network of sociability and his actions in the field of education, so that the press is configured as an instrument of construction and legitimation of the intellectual and, at the same time, means of spreading the phenomenon of public education in the province of Ceará.
\end{abstract}

Keywords: intellectual, education, press, Empire. 


\section{L'ENSEIGNANT AMARO CAVALCANTI ET LA PRESSE DE CEARÁ: UNE LECTURE DE L'INTELLECTUELLE DANS L'EMPIRE BRÉSILIEN}

\section{RÉSUMÉ}

Cette étude a pour objectif d'analyser le processus de construction de la figure d'Amaro Cavalcanti, professeur de latin et avocat installé dans la ville de Baturité, comme intellectuel à la fin du XIXe siècle, à travers ses actions et discours publiés dans la presse de Ceará, plus spécifiquement dans le périodique Cearense. A cet effet, nous cherchons à identifier son rapport sur le système éducatif des États-Unis d'Amérique et la proposition de réforme de la province de Ceara, l'évolution des rôles et des postes de direction dans la scène publique. Identifier l'itinéraire de Amaro Cavalcanti périodique possible de comprendre votre sociabilités réseau et leurs actions dans le domaine de l'éducation, de sorte que la presse est configuré comme un outil de construction et la légitimité de l'intellectuel et en même temps, les moyens de diffusion du phénomène de l'éducation publique dans la province de Ceará.

Mots-clés: intellectuel, education, presse, Empire. 


\section{INTRODUÇÃO}

O interesse em investigar a figura de um intelectual no século XIX surgiu quando identificávamos, nos jornais da região Nordeste, escritos de sujeitos da instrução pública, no Império. Entre esses escritos, encontra-se o relatório de instrução pública do professor Amaro Cavalcanti, no jornal Cearense, em 1881, o qual trata do sistema de ensino dos Estados Unidos da América e da proposta de reforma para a província do Ceará. De acordo com esse periódico, em Ofício de 29 de julho de 1880, n. 1993, Amaro Cavalcanti, professor de Latim em exercício, na cidade de Baturité, província do Ceará, foi comissionado pelo presidente de província, o senador André Augusto de Pádua Fleury, para estudar o sistema de instrução elementar nos Estados Unidos da América.

A partir dessa viagem e do relatório publicado no jornal, buscamos dar visibilidade a esse sujeito, identificando a carreira professoral nos últimos anos do Império. De acordo com o Cearense, de 1881, no tempo em que esteve em Nova York, para investigar assuntos da instrução pública, graduou-se em Direito na Albany Law School, pois, até então, exercia a advocacia como advogado provisionado4. Ao retornar à província assumiu a Direção Geral da Instrução Pública da província do Ceará no ano de 1881. Já no ano de 1883, foi designado pelo Ministro do Império para reger uma turma de Latim do $2^{\circ}$ ano do Colégio Pedro II, Rio de Janeiro, e, em 1891, foi eleito deputado federal. Professor, advogado e político, Amaro Cavalcanti merece estudos sobre sua trajetória e sua produção pedagógica.

\footnotetext{
4 Segundo publicação do Cearense de 2 de fevereiro de 1876, Amaro Cavalcanti atuava no foro de Baturité. Também exerceu o cargo de delegado, quando esse periódico publicou a sua exoneração (CEARENSE, 4 de outubro de 1876). Atuar como advogado provisionado ou rábula, no Brasil, era aquele que não possuia formação acadêmica em Direito (bacharelado), obtinha a autorização do órgão competente do Poder Judiciário (no período imperial), ou da entidade de classe (primeiro do Instituto dos Advogados; a partir da década de 1930 da Ordem dos Advogados do Brasil - OAB), para exercer, em primeira instância, a postulação em juízo. Era, então, expedida, a pedido do pretendente, uma Provisão, que tornava habilitado o rábula a pleitear em juízo. O sistema foi recepcionado pela OAB, quando de sua criação, no ano de 1930, vigendo até a extinção do sistema, nas décadas de 1960-70, quando a advocacia passou a ser prerrogativa exclusiva dos bacharéis em Direito.
} 
Embora haja a ausência de pesquisas para a História Política no Nordeste e no Brasil sobre este sujeito que faz intercessão com a História da Educação, o marco temporal e o campo desta pesquisa são delimitados em razão dos limites propostos para este trabalho. Assim, para compreender o processo de construção da figura de Amaro Cavalcanti como intelectual no final do século XIX, por meio de suas ações e discursos sobre ele na imprensa do Ceará, mais especificamente no periódico Cearense, o ponto de partida é a sua viagem ao exterior e sua repercussão no contexto da província do Ceará, pois, por meio desse acontecimento, houve mudanças na sua atuação na instrução pública. Para tanto, a questão central desse trabalho é: Como Amaro Cavalcanti se fez intelectual? A partir desta, outras indagações emergiram: Como ele efetivou a viagem, inicialmente considerada pedagógica, aos EUA? Como associou o interesse pelo Direito e pela Instrução Pública? Do que trata o relatório de instrução publicado no Cearense e como está organizado esse relatório dado a ler no jornal Cearense? Quais as instituições educacionais que visitou? Como se configura o jornal Cearense, em que o relatório foi publicado? E por que foi publicado nesse suporte? Qual a rede de sociabilidade de Amaro Cavalcanti? Qual é o seu lugar na sociedade cearense?

As interrogações acima servem de roteiro para a compreensão do registro de um sujeito particular, professor secundário do Nordeste, que fez uso da instrução pública e de sua rede de sociabilidade como formas de alcançar posição e capital social. O interesse por Amaro Cavalcanti se justifica por trazer à tona uma experiência singular que nos faz pensar como a instrução pública, no Império, contribuiu para a construção do intelectual. Para atingir o objetivo proposto, o de compreender a sua trajetória, sua rede de sociabilidade e o processo de sua construção como intelectual no final do século XIX, por meio de suas ações e discursos sobre ele publicados na imprensa do Ceará, faz-se necessário considerar o suporte no qual os discursos foram publicados, atentando para a circulação de notícias sobre esse sujeito, bem como o movimento que fez durante o período em que foi professor de Latim e a repercussão da sua viagem aos EUA até o fim do ano de 1881, assuntos propagados pela imprensa. 
Investigar sobre personagens - homens e mulheres - que deixaram suas marcas em diversos espaços e tempos situa esse tipo de trabalho no âmbito de uma biografia de intelectuais/história de intelectuais, que pode ser compreendida como uma prática de escrita da história. Esse campo de investigação emergiu ainda na França, no final da década de 60 do século XX - conforme anuncia Sirinelli (2003) -, quando alguns pesquisadores começaram a voltar seus olhares para esse fenômeno. Faz-se necessário ressaltar que o direcionamento de pesquisas para a história do intelectual está na perspectiva de "[...] um campo histórico autônomo que, longe de se fechar sobre si mesmo, é um campo aberto, situado no cruzamento das histórias política, social e cultural" (SIRINELLI, 2003, p. 232). Até então não se pode ignorar que se estudavam figuras ilustres pertencentes às elites, entretanto, tomava-se como referência uma história positivista. Em razão da mudança de pontos de vista para tratar e conhecer sujeitos não ilustres, acontecimentos e objetos do cotidiano, por meio da Nova História Cultural, o olhar se voltou para as massas, na perspectiva da micro história, de modo que houve um "silenciamento dos intelectuais", que passaram a ser tratados pelos historiadores como "subobjeto da história", considerados um grupo social reduzido, indistinto e elitista. A partir do renascimento da história do político, ressignificado pela representatividade coletiva, foi dado outro status para a história do intelectual, o que ocorreu pelo entrelaçamento da história política, social e cultural, como já foi dito.

A categoria intelectual, conforme Bobbio, foi disseminada a partir do caso Dreyfus 5 , no final do século XIX, embora sempre tenha existido em todas as sociedades e tempos com outros nomes, a exemplo dos "sábios, doutos, philosophes, literatos, gens de lettre, ou mais simplesmente escritores, e, nas sociedades dominadas por um forte poder religioso, sacerdotes e clérigos" (BOBBIO, 1997, p. 11). O caso Dreyfus inaugurou tal categoria por meio de protestos de autoria de escritores e literatos, como Émile Zola e Marcel Proust, publicados na imprensa, confirmando a relação entre intelectuais e imprensa.

5 Cf. Novaes (2006); Bobbio (1997). 
Ao tratar de intelectuais brasileiros na História da Educação, Gondra (2007) conecta instrução, intelectualidade e império para apresentar o percurso de homens que utilizam a "reflexão e pena" para abordar diversos assuntos e, assim, garantir o progresso da nação. Estes homens, denominados de intelectuais, faziam uso da condição em várias ordens, como médica, jurista, militar, familiar, religiosa, a exemplo de "padres que ocupam ao mesmo tempo a condição de professores e deputados", para discorrer sobre temas caros à sociedade da época, educação, ciência, escravidão... Nessa perspectiva, Simões Júnior et al. (2009, p. 8) situam o grupo de intelectuais, tomando a imprensa no século XIX como lugar de composição para esse grupo:

É nesse contexto que a militância dos intelectuais brasileiros se fortalece e se torna cada vez mais legítima, ao se manifestar e se posicionar em relação aos mais diversos assuntos, desde as questões do cotidiano da cidade até os grandes temas que mobilizavam o cenário internacional, através de seus artigos e crônicas. Literatos, médicos, engenheiros, cientistas, educadores, discutiam questões relativas aos seus campos de conhecimento, que, então, começavam a se delimitar, ao mesmo tempo que diagnosticavam a realidade brasileira e propunham projetos para o futuro do país.

Gondra (2007, p. 7) ainda nos auxilia a compreender a figura do intelectual, ao explicar que há um

[...] múltiplo pertencimento, [que], pode ser considerado um dos atributos dos intelectuais, o que nos leva a tentar descrever este tipo de sujeito social como aquele que se debruça sobre um amplo arco de problema que afeta o funcionamento da sociedade como um todo.

Assim, os intelectuais usam a palavra (poder ideológico) buscando "influenciar o comportamento de quem lê ou escuta, para induzi-lo a agir, mais de um modo que do outro" (BOBBIO, 1997, p. 12), sendo assim, uma das funções principais do intelectual é a de escrever. A conduta do intelectual é caracterizada por uma forte vontade de participar das lutas políticas e sociais do seu tempo. 
Essa figura passa a ser vista como "um indivíduo dotado de uma missão moral superior, que compreendia educar e contribuir para a unidade nacional" (ANDRADE, 2015, p. 14). Nesse sentido, Wolff (2006, p. 47) ressalta que, para o aparecimento do intelectual, se fizeram necessárias três condições: "um certo tipo de sujeito social, um certo tipo de objeto (o universal) e um certo espaço onde ele possa se exprimir”.

No âmbito da biografia de intelectuais, Pallares-Burke (2005, p. 19) esclarece que o estudo sobre uma personagem célebre deve atentar para as ideias e não apenas para a história de vida. Sob tal ângulo, a biografia:

[...] pode ser definida como o estudo do desenvolvimento das principais ideias e interesses do protagonista, observando-se mais sua jornada do que seu destino final, e tentando-se explicar como um dado escritor, artista ou estudioso se tornou a pessoa que a posteridade conhece.

Ao verificar a jornada de um sujeito na constituição do estatuto de intelectual, os estudos de Simões Júnior et al. (2009) e Engel et al. (2015) demonstram a imprensa como lugar da constituição e da consolidação do campo intelectual durante o século XIX. Os periódicos, nessa época, divulgavam ideias, lutas políticas e literárias, na atuação político-social e na organização de grupos de intelectuais. Assim, a imprensa torna-se uma instância de consagração do intelectual, pois, de acordo com Bourdieu (1996, p. 70), "o desenvolvimento da imprensa é um indício, entre outros, de uma expansão sem precedente do mercado de bens culturais, ligada por uma relação de causalidade circular ao afluxo de uma população".

Indo na mesma direção de Gondra (2007), que utilizou as três condições supracitadas para refletir sobre a figura do intelectual a partir do Dr. Abílio César Borges por meio dos três "Is" (Instrução, Intelectual, Império), tomo igualmente essa referência, apenas acrescentando um quarto "I" (Imprensa) para analisar o caso de Amaro Cavalcanti, pois, na medida em que era professor de Latim, tornou-se bacharel em Direito, escreveu sobre instrução e utilizou a imprensa 
como espaço de circulação de suas ideias. Neste estudo, a imprensa é considerada como veículo de poder que atua em circunstâncias em que há distanciamento entre o dito e o acontecido, tornando-se este veículo, portanto, um instrumento de construção para essa figura e, ao mesmo tempo, meio de divulgação do fenômeno da instrução pública na província do Ceará.

Para a análise do relatório da instrução pública de Amaro Cavalcanti foi justaposto com outros documentos, a exemplo do relatório de presidente de província, jornais do Ceará e compêndios dos Estados Unidos da América, na perspectiva do processo de produção, circulação e apropriação ou reelaboração de ideias. Nesta perspectiva, o relatório de viagem sobre instrução pública será compreendido por “[...] não haver prática ou estrutura que não seja produzida pelas representações, contraditórias e em confronto, pelas quais os indivíduos e os grupos dão sentido ao mundo que é o deles" (CHARTIER, 1991, p. 177). Desse modo, é necessário observar os seus entornos de produção, em particular, as relações com o autor, obra e contexto, de modo que o relatório será tratado como parte integrante de ideias, de crenças e de posicionamentos que influenciaram Amaro Cavalcanti.

\section{BREVE DADOS DE AMARO CAVALCANTI}

Amaro Cavalcanti Soares de Brito nasceu em 15 de agosto de 1849, no município de Caicó, comarca do Seridó, da província do Rio Grande do Norte, sendo filho de D. Ana Cavalcanti e de Amaro Soares Cavalcanti de Brito, professor de ensino primário. De origem pobre, ele saiu da cidade, ainda jovem, ao ter se apaixonado por uma das filhas do professor Joaquim Apolinar Pereira de Brito, que proibiu o namoro em razão da sua condição social, mesmo sendo um estudioso em Latim, aspecto muito importante para a época (CIRNE, 2004).

Ao partir da sua cidade natal, acompanhou um comerciante do município de Itabaiana, na Paraíba, onde exerceu a atividade de caixeiro. Trabalhou 
também no Recife, seguindo a mesma atividade do comércio. Mudou-se para São Luís, no Maranhão, e fez os preparatórios, onde obteve o lugar de professor de Latim em um colégio particular. A sua ida à Fortaleza se deu na ocasião da ordenação de João Maria, seu irmão mais velho, quando tomou conhecimento que, em Baturité, estava aberta vaga na cadeira de Latim. Assim, participou do concurso e passou a residir e a trabalhar como professor nessa cidade. Ao se envolver na política local, escreveu artigos nos jornais Cearense 6 e Pedro II7, livros didáticos e de religião ${ }^{8}$, que lhe valeram reconhecimento. Em 1880 foi comissionado para ir aos Estados Unidos da América para estudar a instrução pública desse país. Enquanto cumpria a missão, cursou Direito na Universidade de Albany, graduando-se em 1881 (IHGB, 2017). A graduação na Universidade de Albany, no estado de Nova York, na época da sua fundação, em 1844, era uma escola normal, com o objetivo de formar professores para uma população em rápido crescimento. Por quase 50 anos, a Escola Normal9 proporcionou uma educação de dois anos a estudantes de todo o estado (UNIVERSIDADE DE ALBANY, 2017). Possivelmente, em razão deste tipo de educação, Amaro

\footnotetext{
${ }^{6}$ Informações sobre esse periódico será tratado posteriormente.

7 Pedro II, órgão conservador, foi lançado no dia 12 de setembro de 1840 , sob o título D. Pedro II. Publicado às quartas-feiras e sábados, com o preço de assinatura de 500 réis mensais e números avulsos eram vendidos por 80 réis. Impresso por Galdino Marques de Carvalho, na tipografia Constitucional, localizada na rua dos Quarteis. Já no segundo número o jornal passou a intitular Pedro II, o do dia 16 de setembro, e foi publicado pela tipografia Constitucional de Albuquerque, situada na rua dos Mercadores, n.10. Ao longo da circulação deste periódico, até 1889, houve mudanças de tipografias, a exemplo da Tipografia Cearense, e passou a ser diário.

8 Amaro Cavalcanti também escreveu os seguintes livros, conforme o IHGB (2017): Educação elementar nos Estados Unidos, Ceará, 1881; Meio de desenvolver a instrução primária nos municípios rurais, RJ, 1884; Finances du Brésil, 1889; The Brasilian language and its agglutination, RJ, 1884; Resenha financeira do ex-império, RJ, 1890; Política e finanças, RJ, 1892; O meio circulante nacional, RJ, 1893, 2 vols.; A situação política ou a intervenção do governo federal nos estados da União, RJ, 1893; Regime Federativo, RJ, 1900; A Comissão Parlamentar do Código Civil Brasileiro, RJ, 1901; O arbitramento, RJ, 1901 e 1906; A justiça internacional, RJ, 1902; The Federal Judiciry in Brazil, and the United States of América, Filadélfia, 1911; Pan American questions, RJ, 1913; A vida econômica e financeira do Brasil, RJ, 1915; Natureza e forças econômicas do Rio Grande do Norte, RJ, 1916; A sociedade das nações, RJ, 1920.

9 "A Escola Normal do estado de Nova York foi estabelecida por um ato legislativo em 1844, "para a instrução e prática de Professores de Escolas Comuns, na ciência da educação e na arte de ensinar". Foi estabelecida pela primeira vez por cinco anos, como um experimento, e entrou em operação em 18 de dezembro de 1844, em um edifício fornecido gratuitamente pela cidade de Albany, e temporariamente equipado para esse fim" (Tradução livre) (BARNARD, 1851, p. 201).
} 
Cavalcanti, professor de Latim, se sentiu atraído pela rápida formação em Direito.

Quando retornou à província, Amaro Cavalcanti pediu exoneração da função de professor de Latim e assumiu a Direção Geral da Instrução Pública da província do Ceará no ano de 1881 e atuou, simultaneamente, como advogado. Ainda no ano de 1881, no dia 10 de novembro, o jornal Pedro II, órgão conservador, da cidade de Fortaleza, publicou a notícia de seu casamento: "O nosso presado amigo e colega Dr. Amaro Cavalcanti casou-se na cidade de Baturité com $\mathrm{Exm}^{\mathrm{a}} \mathrm{Sr}^{\mathrm{a}} \mathrm{D}$. Henriqueta Catão Cavalcanti, filha do falecido, juiz de direito d'aquella comarca, Dr. Catão" (PEDRO II, 1881, p. 1). Em 1883, tornou-se professor de Latim no Colégio Pedro II, no Rio de Janeiro.

A sua carreira de homem público ascendeu ainda mais na capital do Império e da República, onde atuou como Deputado na Assembleia Legislativa, pelo Ceará; Senador, pelo Rio Grande do Norte; e Prefeito da cidade do Rio de Janeiro, estes dois últimos na República. Ocupou diversos cargos importantes em ministérios e conselhos, na República, e também publicou livros nas áreas jurídica e fiscal. Amaro Cavalcanti faleceu no Rio de Janeiro, em 28 de janeiro de 1922.

\section{CEARENSE E AMARO CAVALCANTI: UM JOGO DE VISIBILIDADE?}

O periódico Cearense foi o lugar onde Amaro Cavalcanti teve sua vida profissional publicizada. Nele encontram-se o relatório da instrução pública, divulgado em diversas etapas, anúncios da publicação dos seus livros e da sua atuação como advogado. Também foram noticiadas, nesse jornal, matérias sobre a viagem aos Estados Unidos da América e sobre sua ascensão na carreira da instrução pública. Por meio desse veículo, é possível acompanhar a trajetória profissional de Amaro Cavalcanti.

Cearense foi um órgão liberal e teve o seu primeiro número impresso em 
04 de outubro de 1846. As publicações eram feitas aos domingos, na rua da Amélia, n. 14, na tipografia de F. L. Vasconcelos. Depois passaram a ser diárias. "O periódico Cearense era de propriedade do Senador Pompeu. Além de ter sido simultaneamente diretor do Liceu e da Instrução Pública cearense, em 1844, Pompeu foi padre e um dos maiores representantes das idéias liberais da Província no século XIX" (MADEIRA, 2002, p. 3). Com o passar dos anos, esse jornal foi publicado e vendido em uma tipografia e escritório na rua Formosa, n. 19, instalado em Fortaleza, capital da província cearense. De acordo com Fernandes (2004, p. 36-37):

Logo após a proclamação da República, em 1889, até o último número, em 25 de fevereiro de 1891, os idealizadores, entre eles o conselheiro Rodrigues Junior, substituíram a epígrafe "órgão liberal” por "órgão democrático". O Cearense foi fruto do jornal Vinte e Três de Julho, de 1840, órgão político fundado para comemorar a ascensão liberal à presidência da província cearense, com a posse do senador Alencar, e do jornal A Fidelidade, de 1844, substituição do Vinte Três de Julho, ambos publicados em Fortaleza, sob a direção e redação de Frederico Pamplona, Tristão Araripe e do senador Thomaz Pompeu, que, dois anos depois fundaram $O$ Cearense, com o apoio dos redatores Miguel Ayres, João Brígido, Dr. José Pompeu, Conselheiro Rodrigues Junior e João Câmara, que atuou como gerente até 1880 , ficando no lugar o Dr. Paula Pessoa (FERNANDES, 2004, p. 36-37).

Esse jornal era um órgão representante dos ilustrados da Província, sendo compreendido na perspectiva de Madeira (2002, p. 3) como

[...] campo social, como tantos outros - a exemplo das secas, epidemias, embates políticos e religiosos - era disputado nos discursos de juristas, cientistas, religiosos, liberais, filantrópicos, maçônicos e políticos, os quais buscavam voz e lugar no cenário social cearense.

Neste periódico há anúncios, comunicados, despachos, editais, avisos de todos os gêneros, a exemplo da pecuária, instrução pública, clima, exportação, importação, eleições, atos legislativos, saúde... As publicações vinham tanto das 
freguesias da província do Ceará quanto de regiões do país e do mundo, configurando-se como uma sociedade de correspondência. Tomando o jornal como o lugar de referência de visibilidade e, assim, da constituição do homem público, em que as relações de poder se configuram como determinantes para a construção da figura do intelectual, Amaro Cavalcanti pode ser compreendido por meio desse suporte onde se propagou no cenário educacional e político ou político e educacional da província do Ceará.

Em meio aos discursos, Amaro Cavalcanti começou a ter visibilidade nos debates políticos na imprensa ainda na década de 70 do século XIX, de modo que foi visto como professor partidário do conservadorismo "[...] pela attitude ostensiva que tem assumido em face dos negócios políticos daquela cidade ${ }^{10}$, sendo eleito para ser presidente da junta paroquial (CEARENSE, 13 de abril de 1876, p. 3). Essa notícia tomou como referência a publicação no jornal Constituição ${ }^{11}$, promovendo debate entre os leitores, nas edições seguintes do Cearense. Anteriormente, porém, em 25 de julho de 1874, este jornal publicou a opinião de Amaro em resposta ao jornal Tribuna Catholica - órgão político do partido católico - sobre uma conferência a respeito de religião, em que o professor afirma a sua imparcialidade política e religiosa. Na réplica emitida/publicada em "A Pedidos", o professor não aceita o juízo de ex cathedra para falar a respeito de seus erros, opiniões e crenças, sendo este acusado de "agradar a Deus e ao Demônio". Ao passo que manifestava sua posição político-partidária, a da imparcialidade, Amaro Cavalcanti tornava públicos os seus escritos sob os títulos: A Religião (1874), A meus discípulos (polêmica religiosa) (1875) e Livro popular (1879). Este último trata de uma obra educacional, que, de acordo com a primeira página, na sessão "noticiário", se refere ao seu lançamento no Cearense, no dia 30 de maio de 1880, antes da sua partida para os EUA:

\footnotetext{
10 Mantenho a ortografia da época.

${ }^{11}$ Folha política, comercial e noticiosa. Este periódico apresenta publicações oficiais do governo e notícias semelhantes ao Cearense. Circulou de 1860 a 1889.
} 
Livro popular - com este título acaba de sahir a luz da publicidade um livro destinado ao ensino nas escholas de primeiras letras e devido a hábil pena do ilustre professor de latim de Baturité Amaro Cavalcanti.

É uma obra bem escripta, perfeitamente accommodada a inteligencia da infância e assaz recomendável pela feliz disposição de matérias, cujos principios elementares são de grande alcance no ensino primario.

O Conselho Litterario, em sessão de 27 de abril ultimo, decidindo com justiça sobre o real merecimento d'esta importante obra deu-lhe sua aprovação e mandou que fosse introduzida como livro de leitura para as classes mais adiantadas nas escholas primarias.

É louvável o interesse que manifesta pela instrucção publica o Sr. professor Amaro Cavalcanti e é de esperar que os professores e paes família correspondao aos esforços do autor, animando a publicação de obras de tanta utilidade (CEARENSE, 30 de maio de 1880, p. 1).

Algumas perguntas surgem com a publicação dessa notícia: quando Amaro escreveu essa obra? Teria sido no ano anterior, quando esteve afastado das suas atividades docentes por meio de uma licença de um ano para tratar de sua saúde? De acordo com o jornal Cearense do dia 16 de janeiro de 1879, foi concedida a licença para o professor, sendo esta publicada na segunda página, entretanto, não foi revelada a doença e nem o tratamento. Ou teria sido iniciado ainda no ano de 1876, quando também esteve afastado pelo mesmo motivo? O jornal Constituição, de 17 de agosto 1876, informa, na primeira página, por meio da Lei n. 1721, de 2 de agosto deste ano, que o professor teve sua licença concedida por um ano, com vencimento, para tratar da sua saúde. Por que um professor de Latim que lecionava no ensino secundário escreveu uma obra destinada ao ensino primário? Duas pistas são a conferência popular a respeito da Escola Popular realizada em 28 de junho de 1874 (CEARENSE, 1874, p. 3) e a sua atuação como presidente no Club Literário, fundado em 1875, na cidade de Baturité, onde "haverá uma eschola nocturna para a aprendisagem do povo, e mais tres, de preparatorios, francez, inglez e geometria” (CEARENSE, 1875, p. 3).

A partir dessa obra didática, Amaro Cavalcanti teria dado os seus primeiros passos para se tornar um intelectual? A inserção no tema instrução por meio do suporte livro surgiu como problema na agenda social, por ser "[...] objeto 
de atenção regular de parte da intelectualidade desde o século XIX" (GONDRA, p. 2007).

Amaro Cavalcanti não se limitou tão-somente a escrever uma obra de caráter didático. Assim, aos 31 anos de idade, viajou aos Estados Unidos da América sob o oficio de 29 de julho de 1880, de n. 1993, e comissionado pelo presidente de província da época, o senador André Augusto de Pádua Fleury, para estudar o sistema de instrução elementar deste país. A notícia de sua partida é do dia 30 de julho de 1880 do periódico Cearense:

Segue para América do Norte o Sr. Amaro Cavalcanti professor de Latim na cidade de Baturité.

O digno professor vai estudar a instrucção n'aquelle paiz.

Desejamos-lhe próspera viagem (CEARENSE, 30 de julho de 1880, p. 2).

Na página 4 dessa mesma edição, há um discurso laudatório de despedida para Amaro Cavalcanti, assinado por 72 pessoas, entre eles, professores, tenentes, coronéis, advogados, capitães, confortando-o e justificando-lhe por não ter sido preceptor "de maiores conquistas", sendo a causa disto a "[...] inndiferença criminosa de nossa sociedade relativamente a este tesouro precioso e sem igual a que chamamos - educação civil e moral -, embora, apesar de tal fato, ter se tornado cidadão virtuoso" (CEARENSE, 30 de julho, 1880, p. 4).

Durante a sua estada nos EUA, o Cearense não publicou notícias sobre Amaro Cavalcanti. Nesse mesmo periódico, entretanto, há uma propaganda do dia 30 de janeiro sobre o lançamento do Libertador ${ }^{12}$ para os próximos dias do ano de 1881 e a divulgação de uma lista de acionista em que o nome de Amaro

\footnotetext{
${ }^{12}$ Libertador, Órgão da Sociedade Cearense Libertadora, teve a sua primeira edição publicada no dia $1^{\circ}$ de janeiro de 1881. Publica-se semanalmente, e assigna-se a razão de 2:0oo réis por trimestre. $\mathrm{O}$ número avulso era vendido por 40 réis. Possui oito páginas e era impressa na Tipografia Brasileira por Joaquim Lopes Verçosa.
} 
Cavalcanti também está presente. Esse dado revela que a imprensa foi utilizada por ele como estratégia de propagação das suas ideias, sendo assegurada sua participação como um dos membros do referido jornal, mesmo estando distante fisicamente.

Ao retornar ao Brasil, Amaro Cavalcanti percebe que o cenário político do Ceará era outro: "Volto ao Ceará com um Brasil novo, meio desconhecido e de política contrária" (CAVALCANTI, 6 de julho de 1881, p. 3), conforme carta escrita sob sua pena, no Pará, a Salvador de Mendonça ${ }^{13}$ na Corte. O presidente de província não era o mesmo, sendo este agora o senador Pedro Leão Velloso. Os deslocamentos dos presidentes de província são explicados em razão da ausência de um mandato, de modo que podiam ser exonerados ou pedir afastamento à revelia. A indicação deles está associada aos gabinetes e as tentativas de manter governabilidade, com acordos provinciais, o que garantia o controle e a centralização do poder imperial. A percepção de um novo cenário político está em evidência na sua carta, de modo que solicita ao destinatário, Salvador de Mendonça, uma carta de apresentação ao Presidente de Província, de alguém importante. Antes de tal pedido, entretanto, Amaro Cavalcanti anuncia a conquista obtida em Nova York - o diploma de bacharel em Direito - como elemento de relevância para o seu retorno ao Ceará:

Minha formatura realizou-se e não só isto: a suprema corte do Estado de N. Y. mandou passar me certificar de Consels at Law em três cortes do Estado. Isto creio foi devido ao professor Learned que era ao mesmo tempo cheaf Justice daquela corte. Me disse que a lei não me excluia sendo estrangeiro. De sorte que sou aprovado no estado de N. York...

$[\ldots]$

Receio que quanto menos ele preste pouca atenção aos meus esforços em favor da comissão que tive de desempenhar; digo isto porque receio sugestões de inimigos políticos.

\footnotetext{
13 Salvador de Menezes Drummond Furtado de Mendonça nasceu em Itaboraí no dia 21 de julho de 1841 e faleceu no Rio de Janeiro no dia 5 de dezembro de 1913. Atuou como advogado, jornalista, diplomata e escritor brasileiro, sendo um dos fundadores da Academia Brasileira de Letras e um dos idealizadores do Movimento Republicano no Brasil.
} 


\begin{abstract}
Diga, pois - Poderá enviar aí da corte carta d'algum ministro (ou pessoa e querida) em meu favor a este Prese? Antemão ser carta de pessoa tal, não precisa tomar incomodo, e de acordo a meu pedido interferir com alguma pretensão sua, então cessa pedido. Como sabe toda franqueza entre nós.

Se acaso, quando for possível deve enviar diretamente ao Presidente pelo próximo vagar, e não a mim. Apenas quero lhe recomendar a Consideração e bondade do Presidente do Ceará, fazendo-me conhecer como a pessoa última e ainda dos Estados Unidos em sua Comissão em bem da Pátria (CAVALCANTI, 6 de julho de 1881, p. 3).14
\end{abstract}

Essa mensagem demonstra um lugar de estratégia, relações de força e interesse que Amaro Cavalcanti utilizou para a busca de reconhecimento ou consagração, na perspectiva de Bourdieu (2004). Se, por um lado, contudo, as assinaturas de apoio publicadas no jornal, a composição do quadro de acionista de um jornal, o pedido de uma carta de apresentação de um sujeito ilustre podem configurar consagração, conforme indica Bourdieu logo acima, por outro lado podem demonstrar os sinais da rede de sociabilidade de Amaro Cavalcanti.

A imprensa tem o seu lugar de destaque no itinerário de intelectual de Amaro quando publica em suas páginas o processo de transição da sua carreira. Da exoneração do cargo de professor à advocacia, o Cearense publicou muito a respeito de Amaro Cavalcanti, a começar pelo recorte do dia 03 de agosto do ano de 1881, cuja notícia apresenta a

\begin{abstract}
Portaria concedendo ao bacharel Amaro Cavalcanti a exoneração que pediu do cargo de professor de latim da cidade de Baturité e declarando suprimida a mesma cadeira, na conformidade da lei de 18 de setembro do ano passado (CEARENSE, 3 de agosto de 1881, p. 1).
\end{abstract}

No dia 18 de agosto de 1881, ele também esteve muito presente nas páginas do periódico, por meio de anúncios sobre conferência e doação de livros a estudantes da cidade de Granja. Conforme esse anúncio (1881, p. 2): “sábado as

14 Carta localizada na Biblioteca Nacional, no Rio de Janeiro, em setembro de 2016. 
7 horas da noite o ilustrado Dr. Amaro Cavalcanti fará no salão da Escola Camões uma conferência sobre Educação". Dois dias depois há outro anúncio sobre essa atividade:

Conferência - Realisa-se hoje, como já noticiamos, no salão da Escola Camões a conferência do ilustrado Dr. Amaro Cavalcanti sobre a educação. O conferenciador está n'altura de desenvolver perfeitamente a these a que se propõe que foi assumpto de sérios estudos seus na viagem que empreendeu há pouco na América do Norte (CEARENSE, 20 de agosto de 1881, p. 2).

No dia 23 de agosto foi publicada a notícia sobre a conferência realizada por Amaro Cavalcanti. O final da publicação merece atenção:

Ao terminar o seu discurso, palpitante de atualidade, o ilustre conferente colheu os mais merecidos aplausos de quantos se achavão presentes.

Associamo-nos com intimo jubilo à esta justa homenagem tributada ao esforço inteligente e desinteressado do Sr. Dr. Amaro Cavalcanti em prol da educação popular cearense (CEARENSE, 23 de agosto de 1881, p. 2).

Amaro Cavalcanti assumiu a Direção Geral da Instrução Pública da província do Ceará antes do seu relatório ser publicado no jornal, conforme as notas dos jornais Cearense e Pedro II, dos dias 3, 4 e 7 de setembro, respectivamente: "Portaria concedendo a exoneração que pediu o Rvd. Dr. João Augusto da Frota do cargo de diretor geral da instrução publica e nomeando para esse cargo o bacharel Amaro Cavalcanti que prestou juramento e tomou posse [...]" (CEARENSE, 4 de agosto de 1881, p. 1). Quanto ao jornal Pedro II (7 de setembro de 1881, p. 1), segue a breve nota: "já prestou juramento e entrou no exercício de diretor da instrução pública da província, para cujo cargo fôra ultimamente nomeado, o ilustrado Sr. Dr. Amaro Cavalcanti”. Embora os periódicos tenham noticiado a posse de Amaro na nova função, o Relatório de 
presidente de província menciona que sua nomeação foi no dia 02 de outubro (CEARÁ, 1881, p. 7).

Os periódicos Cearense, Constituição e Pedro II contribuíram como instância de consagração de Amaro Cavalcanti. A imprensa tem a função de mercado dos bens culturais, tornando-se o lugar por excelência de validação, de consagração do intelectual. Dessa forma, os jornais supracitados e, mais especificamente Cearense, possibilitaram a Amaro Cavalcanti ter visibilidade a partir da ideia de que bens culturais têm donos. Ao utilizar essa estratégia de autopromoção, ele obteve o lugar de autoridade quando o relatório de viagem sobre a instrução pública nos Estados Unidos da América foi publicado nesse periódico. Nesse sentido, não era mais um professor que pronunciava, mas sim um "doutor", embora assinasse ainda como professor em comissão. Conforme o cabeçalho do relatório no jornal (Fig. 1), o relatório é do Dr. Amaro Cavalcanti:

Figura 1 - Cabeçalho do Relatório do Dr. Amaro Cavalcanti.

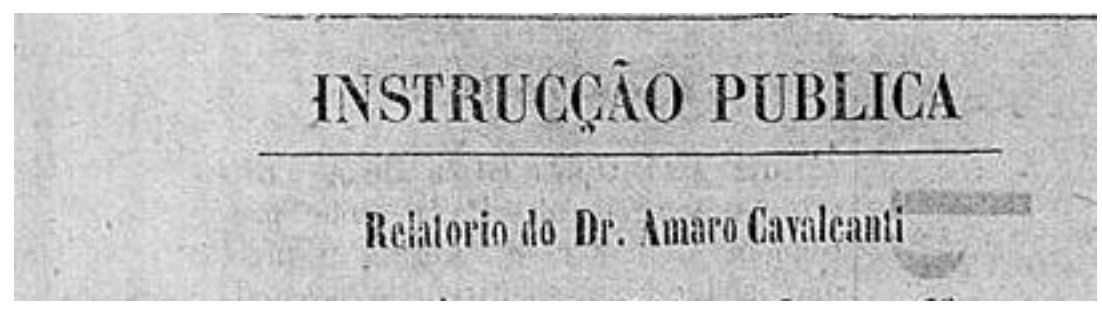

Fonte: Cearense (7 de setembro de 1881, p. 3).

O lugar de enunciação de Amaro Cavalcanti como produtor do relatório sobre a instrução pública pode ser entendido por duas vias. A primeira por meio do axioma divulgado por Benjamin (2012, p. 214), de que " 'quem viaja tem muito que contar', diz o povo, e com isso imagina o narrador como alguém que vem de longe". Mas o que o professor nos contou? Nessa perspectiva, ele se projeta como um educador viajante pedagógico que, durante a segunda metade do século XIX, se deslocava a outros países em busca da modernidade no ensino, a exemplo do argentino Domingo Faustino Sarmiento, em 1845; Horace Mann, em 1843; o chileno José Abelardo Nuñez, no ano de 1878, homens que se dirigiram à 
Europa. Este último também foi aos Estados Unidos. Assim como Celestin Hippeau que atravessou fronteiras para estudar o ensino em diversos lugares Europa, América do Sul e Estados Unidos. Quanto aos brasileiros, há a professora Maria Guilhermina Loureiro de Andrade, que embarcou aos Estados Unidos, em 1883, onde estudou os métodos de ensino; em 1890, os professores Luiz Augusto dos Reis, Manoel José Pereira Frazão e Amélia Fernandes da Costa se deslocaram para a Europa com a mesma finalidade (PINTO, 2011; SCHUELER, 2010; CHAMON, 2008; SILVA, 2013). A segunda via de que falamos diz respeito ao lugar de autoridade - Amaro Cavalcanti tornou-se bacharel em Direito, assumindo o cargo de Diretor Geral da Instrução Pública na província após a sua chegada. A mudança de cargo ocorreu mesmo antes da publicação do seu relatório, o que faz pensar na sua rede de sociabilidade, que já estava estabelecida na relação das pessoas que assinaram o discurso laudatório da sua partida para os EUA, publicado no Cearense, como acionista do jornal Libertador, na carta endereçada a uma pessoa influente na Corte e, por fim, nas publicações no Cearense sobre suas atividades laborais.

Em meio a esse percurso, a novidade está no acontecimento, em que a integração dos elementos que envolvem Amaro Cavalcanti - o fato de ser educador, a publicação de livros didáticos, sua viagem ao exterior, a formação em Direito, visibilidade no jornal e sua rede de sociabilidade - se apresenta como estratégia de propaganda, tornando-se um modo de assegurar a sua ascensão a um poder. Para esse educador, a visibilidade e o prestígio no cenário cearense transformaram-se em mecanismo para o estatuto de intelectual.

\section{O RELATÓRIO SOBRE A INSTRUÇÃO PÚBLICA DOS EUA, DE AMARO CAVALCANTI}

Quando se lê o relatório da instrução pública dos EUA em um jornal do Ceará, pode-se pensar imediatamente sobre a visão de América de Amaro Cavalcanti. Pode-se ainda imaginar o que ele viu, fez e leu sobre a instrução 
elementar dos EUA, a sua contribuição para a instrução pública cearense. O imaginário que circunda essa viagem é o que motiva conhecer o conteúdo desse material produzido por um professor de Latim, de Baturité.

No dia 02 de agosto de 1881, esse periódico anunciou a chegada de Amaro Cavalcanti, como um relato de viagem oficial. O relatório foi publicado parcialmente, como se fosse um folhetim, seja para prender a atenção dos leitores, seja pela própria estrutura do jornal. A publicação neste formato não apresentava, entretanto, a experiência e ou observação de um viajante a uma terra estrangeira, pois, entende-se que um relatório de viagem trata do visto e do vivido. O relatório, entretanto, tão-somente expunha informações coletadas de outras fontes.

As viagens pedagógicas potencializam uma atitude comparativa, detectam semelhanças e diferenças, além de possibilitar uma reflexão do espaço cultural da nação do viajante. Os viajantes na e pela condição de professor comissionado tinham uma série de atribuições e encargos que outros viajantes não enfrentavam. A estes cabiam, segundo Mignot e Silva (2011, p. 437):

visitar as escolas, observar e estudar os métodos, técnicas e arquitetura de locais de ensino, escrever relatórios descrevendo tudo, além de remeter os materiais e objetos interessantes para o ensino no Brasil. Tais atribuições sugerem pensar a viagem em missão oficial como parte de uma troca entre os envolvidos, no sentido de dom e contradom, uma vez que, se, por um lado, recebia-se financiamento e custeio de hospedagem e deslocamentos, por outro, havia uma série de obrigações e encargos, no sentido de retribuir aqueles que financiavam a viagem.

De acordo com as prescrições acima a respeito de uma viagem pedagógica, a escrita do relatório de Amaro Cavalcanti não se configura como a de um relato de viagem ou de suas observações e experiência sobre a instrução pública estadunidense. Esse gênero discursivo exige o uso na primeira pessoa do singular, já que o responsável por sua produção é o observador e ou viajante. $\mathrm{O}$ autor, no entanto, utilizou a primeira pessoa do plural para fazer menção aos 
extratos retirados de outras fontes. $O$ texto não se refere às percepções derivadas de seu testemunho, visita ou qualquer outro tipo de contato pessoal.

No retorno da sua viagem, Amaro Cavalcanti apresentou o relatório ao presidente de província, o senador Pedro Leão Velloso, e foi publicado no jornal Cearense a partir do dia 07 de setembro de 1881, conforme anuncia em nota 0 redator na primeira página:

\footnotetext{
Instrucção Pública - Na seç̧ão que abrimos sob esta epigraphe, começamos hoje a publicar o importante relatório do Sr. Dr. Amaro Cavalcanti.

É escusado chamar a atenção dos leitores sobre este trabalho que se recomenda pela importancia do assumpto e pelo nome do author que entrega à apreciação publica o fructo de suas laboriosas e acuradas investigações (CEARENSE, o7 de setembro de 1881, p. 1).
}

O relatório da instrução pública dos Estados Unidos está dividido em três partes. Na primeira parte, Amaro Cavalcanti tratou da educação em geral (marcha da educação - antes da escola e na escola, programa do curso normal teórico; sobre método escolar; objeto da educação; educação física; educação intelectual; educação moral; educação religioso; grande mal contra a educação; ensino obrigatório). No seu texto, Platão, Edmund Burke, H. Spencer circulam, dando aporte para suas ideias acerca da educação. Nele ainda há a descrição do uso dos objetos por meio da observação, que possivelmente pode ser atribuída ao método lição de coisas. Ao término dessa parte, Amaro Cavalcanti faz o seguinte alerta: "As razões, que ora expendemos, não são exclusivamente pessoaes, resumem a sabia opinião de todas as autoridades, que se tem occupado da materia" (CEARENSE, 21 de setembro de 1881, p. 3).

A segunda trata da educação nos Estados Unidos da América. Nela Amaro Cavalcanti faz o seguinte prólogo:

Não é certamente dado as estreitas proporções de um acanhado relatório conter informações completas ou assaz satisfatórias acerca de 


\begin{abstract}
tão vasto assumpto - qual o da educação Nort'Americana. Nem mesmo um livro, porem, somente muitos volumes poderião abranger noticia assaz exacta a respeito.

Accresce ainda, que a honrosa comissão, que nos propomos executar, limita-se ao ramo exclusivo da instrucção elementar, e nesta, em especial, aos factos, methodos, praticas, que pareção de maior utilidade aos interesses da educação elementar cearense (CEARENSE, 21 de setembro de 1881, p. 3).
\end{abstract}

Mesmo sem saber se as informações foram extraídas de suas interpretações do que leu ou observou, o leitor do Cearense poderia seguir acompanhando o relatório:

\begin{abstract}
Na grande República a leitura, faz por toda a parte, a ocupação ordinária do indivíduo: - o literato e o operário somente se distinguem pela seleção do livro ou grau de saber, mas não certamente pelo amor e devoção constante à gazeta, aos livros e aos pamphleto!

Quem não tem dinheiro para comprar o livro e o jornal, que contem as grandêzas do paiz, vae a biblioteca, aos cafés, aos lugares de recreio, ás typographias, ás fábricas, ás oficinas, ou ás próprias esquinas e postes das ruas, na certeza de que, em cada um d'esses e outros lugares, encontrará gratuitamente assumpto proveitoso para sua cultura, ou antes, alimentação, já preparada, para nutricção de seu coração e de sua intelligencia (CEARENSE, 21 de setembro de 1881, p. 3).
\end{abstract}

O relato sobre a instrução elementar dos Estados Unidos da América foi composto a partir das informações do relatório do Comissário de Bureau de Educação em Washington de 1878, conforme Amaro Cavalcanti enuncia nas primeiras linhas da segunda parte do seu trabalho e na conclusão do seu relatório: "É de myster também acrescentar - que suposto o Relatório, em que fundamos nossos dados estatísticos, referia-se ao anno de 1878, é elle, todavia, o último publicado, e apenas saído do prelo em fins do anno próximo passado" (CEARENSE, 22 de setembro de 1881, p. 3). Sem revelar onde e como Amaro localizou o relatório utilizado para apresentar à província do Ceará os dados da educação estadunidense, este foi o mais recente, devido ao ano de publicação do 
governo do Washington. O documento é de autoria de John Eaton ${ }^{15}$, e dirigido ao Hon. C. Schurz (Secretary of the Interior, Departament of the Interior, Bureau of Education, Washington, D. C.), em novembro/dezembro de 1878, mas apenas publicado em 1880, em razão da aprovação do congresso. Este relatório contém 730 páginas e apresenta dados estatísticos.

No dia 02 de agosto, entretanto, o jornal Cearense faz a seguinte publicação: "visitou os principais institutos de educação nos variados Estados da União; assistiu, examinou, inqueriu com solicitude o que pudesse ser aplicado com proveito à instrução da província" (CEARENSE, 2 de agosto de 1881, p. 3). No relatório publicado no Cearense não há indícios dessas visitas e nem de conhecimento de personalidades da educação estadunidense.

Na terceira e última parte do relatório, quanto às reformas pertinentes à província do Ceará, Amaro Cavalcanti anuncia:

\footnotetext{
Ainda que destituída de autoridade; bem cremos não será reprehensível nossa conduta, si antes de concluir nosso humilde trabalho, suggerirmos algumas ideias quanto aos meios de reforma e melhoramentos, que ora reclama a instrução elementar da província (CEARENSE, 13 de outubro de 1881, p. 3).
}

Nessa parte, ele aborda o salário dos professores; o ensino primário (saber ler, escrever e contar); criação de escola normal, de gramática, visita e inspeção escolar. Nessas seções, Amaro Cavalcanti apresenta sua percepção, possivelmente fundada no seu cargo de professor e nas comparações com a instrução dos Estados Unidos da América.

Quanto à escola normal, esta requerida e defendida por Amaro

\footnotetext{
15 Sob sua autoria, John Eaton produziu nove relatórios anuais sobre a situação da educação estadunidense. John Eaton Jr. nasceu em o5 de dezembro de 1829, em Sutton, N. H., EUA e morreu em o9 de fevereiro de 1906, em Washington, D. C. Foi um educador estadunidense, segundo comissário da educação estadunidense no período de 1870 a 1886 e atuou como o primeiro estadunidense superintendente escolar para escolas públicas em Porto Rico (THE EDITORS OF ENCYCLOPÆDIA BRITANNICA, 2017).
} 
Cavalcanti, foi criada sob a lei n. 1790 de 28 de dezembro de 1878, e sancionada um ano após. O lançamento da pedra fundamental, no entanto, tão somente ocorreu em 1881, conforme noticiou o Cearense do dia 02 de outubro de 1881: "Vamos construir a Escola Normal; levantar a escola onde se eduquem educadores da infância”. No dia 04 de outubro outra notícia estampou o jornal, evidenciando personalidades da província cearense, “[...] o assentamento da primeira pedra do edifício destinado a uma Escola Normal, a praça do Marquez do Herval" (CEARENSE, o4 de outubro de 1881, p. 1). Enquanto nos Estados Unidos da América havia 156 escolas normais, no Ceará essa só surgiu em 1881. De acordo com Amaro Cavalcanti, em seu relatório, publicado no dia 15 de outubro de 1881 no jornal, o Instituto Normal do Ceará deveria ser criado a partir do modelo estadunidense, tendo três anos de duração, métodos de ensino, organização do espaço escolar semelhante ao do país visitado.

Faz-se necessária uma ressalva a respeito do que o relatório de Amaro Cavalcanti aponta como um modelo de escola normal nos Estados Unidos da América. Embora a obra de Henry Barnard intitulada Normal School, and other Institutions, Agencies, and Means desingned for the Professional Education of Teachers (1851) não tenha sido apontada por Amaro Cavalcanti como leitura para a produção do seu relatório, esta apresenta a história da escola normal dos estados deste país, especificamente de Connecticut, Massachusetts, New York, Pennsylvania, Rhode Island, Michigan e British Provinces. Cada instituição de ensino normal destes estados tem a sua peculiaridade e autonomia para legislar o ensino.

\section{CONSIDERAÇÕES FINAIS}

Este estudo compreende-se na perspectiva da intelectualidade e dos relatos de viagens, já que o interesse em investigar Amaro Cavalcanti se deu em razão do seu relatório sobre a instrução pública dos Estados Unidos da América, divulgado no periódico Cearense, em 1881. Focalizar a viagem de um homem do 
Nordeste brasileiro a Nova Iorque, no final do século XIX demonstra a complexidade entre os circuitos e as redes de sociabilidade, problematizando, desta maneira, uma determinada historiografia processadas na capital do Império e/ou outras regiões do sudeste e do sul.

O relatório de instrução pública dos Estados Unidos da América, de autoria de Amaro Cavalcanti, pode apresentar como novidade o relatório do Comissário de Bureau de Educação em Washington de 1878 transcrito, como anunciou seu autor na segunda parte, bem como os encaminhamentos que fez sobre a Escola Normal na província do Ceará, tomando como referência o processo de construção das escolas normal daquele país. Apenas descrevendo as suas reflexões acerca dos dados da instrução estadunidense, o autor do relatório faz comentários, ora comparando as situações distintas entre a província do Ceará e dos EUA, ora ressaltando todo o sistema de ensino desse país, o qual era oposto ao do Brasil.

Se, por um lado, a publicação do relatório no jornal Cearense é uma forma de divulgar os atos administrativos, os quais estão sujeitos ao exame da opinião pública, por outro, o periódico foi o lugar para conceder notoriedade a Amaro Cavalcanti, espaço em que os leitores puderam atentar e acompanhar a fabricação desse intelectual, como educador e político. Nessa perspectiva, o jornal se configurou como "instrumento estruturado e estruturante de comunicação e de conhecimento", no qual se fez valer "o poder das palavras", por meio da "crença na legitimidade das palavras e daquele que pronuncia, crença cuja produção não é a competência das palavras" (BOURDIEU, 2009, p. 15).

Além disso, os anúncios e as notícias sobre Amaro Cavalcanti estão inseridos em uma "ordem do discurso" (FOUCAULT, 2000), os quais estavam revestidos de um poder, o do prestígio, de ser conhecido, de ter seus discursos publicados, e ainda, o de alcançar funções e cargos altos na cena pública, dada sua rede de sociabilidade (casamento e amigos) e de suas ações no campo da instrução, qualificando, assim, a sua posição de intelectual. Por fim, analisar o processo de fabricação de um intelectual, por meio de estratégias de promoção e 
autopromoção, possibilita compreendê-lo a partir de mapeamento do percurso por onde o sujeito trilhou, das obras produzidas e dos laços sociais construídos. No campo da História da Educação brasileira, os estudos sobre intelectuais, imprensa, instrução pública (relatório de viagem), permitem compreender os seus itinerários, apontando as relações entres determinadas esferas sociais e demais sujeitos, em um determinado tempo e espaço.

\section{REFERÊNCIAS}

ANDRADE, Débora El-Jaick. A imprensa como tribuna dos intelectuais no século XIX: o Guanabara em defesa da arte e dos artistas nacionais. In: ENGEL, Magali G.; SOUZA, Flávia F. de; GUERELLUS, Natália de S. (org.). Os intelectuais e a imprensa. Rio de Janeiro: Mauad X: Faperj, 2015.

BENJAMIN, Walter. Magia e técnica, arte e política: ensaios sobre literatura e história da cultura. Tradução Sérgio Paulo Rouanet. 8. ed. revista. São Paulo: Brasiliense, 2012. (Obras Escolhidas, v. 1).

BOBBIO, Norberto. Os intelectuais e o poder. São Paulo: Unesp, 1997.

BOURDIEU, Pierre. As regras da arte: gênese e estrutura do campo literário. São Paulo: Companhia das Letras, 1996.

BOURDIEU, Pierre. Coisas ditas. Tradução Cássia R. da Silveira e Denise Moreno Pegorim. São Paulo: Brasiliense, 2004.

BOURDIEU, Pierre. O poder simbólico. 12. ed. Rio de Janeiro: Bertrand Brasil, 2009.

CAVALCANTI, Amaro. Carta a Salvador de Mendonça, referindo-se ao término do curso de Direito que fizera em Nova York, e solicitando conseguisse no Rio de Janeiro uma carta de apresentaçao para o novo Presidente da Província do Ceará, visto ter desempenhado nos Estados Unidos uma Comissao que trabalhou em prol daquela Província. 6 de julho de 1881.

CEARÁ. Fala com que o exmo. sr. dr. José Julio de Albuquerque Barros, presidente da província do Ceará, abriu a 1.a sessão da 24.a legislatura da Assembleia Provincial no dia 1 de novembro de 1878. Fortaleza, Tip. 
Brasileira, 1879 .

CEARÁ. Relatório apresentado à Assembleia Legislativa do Ceará na sessão ordinária de 1881 pelo presidente da província, senador Pedro Leão Velloso. Fortaleza, Tip. do Cearense, 1881.

CEARENSE. Escola Normal. Fortaleza. 04 de outubro de 1881. Disponível em: http://bndigital.bn.br/hemeroteca-digital/.

CEARENSE. Fortaleza. 02 de fevereiro de 1876. Disponível em: http://bndigital.bn.br/hemeroteca-digital/.

CEARENSE. Fortaleza. 02 de outubro de 1881. Disponível em: http://bndigital.bn.br/hemeroteca-digital/.

CEARENSE. Fortaleza. 03 de setembro de 1881. Disponível em: http://bndigital.bn.br/hemeroteca-digital/.

CEARENSE. Fortaleza. o4 de setembro de 1881. Disponível em: http://bndigital.bn.br/hemeroteca-digital/.

CEARENSE. Fortaleza. 07 de setembro de 1881. Disponível em: http://bndigital.bn.br/hemeroteca-digital/.

CEARENSE. Fortaleza. o9 de outubro de 1881. Disponível em: http://bndigital.bn.br/hemeroteca-digital/.

CEARENSE. Fortaleza. 13 de abril de 1876. Disponível em: http://bndigital.bn.br/hemeroteca-digital/.

CEARENSE. Fortaleza. 14 de novembro de 1875. Disponível em: http://bndigital.bn.br/hemeroteca-digital/.

CEARENSE. Fortaleza. 18 de agosto de 1881. Disponível em: http://bndigital.bn.br/hemeroteca-digital/.

CEARENSE. Fortaleza. 2 de agosto de 1881. Disponível em: http://bndigital.bn.br/hemeroteca-digital/.

CEARENSE. Fortaleza. 20 de agosto de 1881. Disponível em: http://bndigital.bn.br/hemeroteca-digital/.

CEARENSE. Fortaleza. 23 de agosto de 1881. Disponível em: http://bndigital.bn.br/hemeroteca-digital/.

CEARENSE. Fortaleza. 28 de junho de 1874. Disponível em: http://bndigital.bn.br/hemeroteca-digital/. 
CEARENSE. Fortaleza. 3 de agosto de 1881. Disponível em:

http://bndigital.bn.br/hemeroteca-digital/.

CEARENSE. Fortaleza. 4 de outubro de 1876. Disponível em:

http://bndigital.bn.br/hemeroteca-digital/.

CEARENSE. Instrução Pública. Fortaleza. 11 de novembro de 1881.

Disponível em: http://bndigital.bn.br/hemeroteca-digital/.

CEARENSE. Instrução Pública. Fortaleza. 12 de novembro de 1881.

Disponível em: http://bndigital.bn.br/hemeroteca-digital/.

CEARENSE. Instrução Pública. Fortaleza. 13 de novembro de 1881.

Disponível em: http://bndigital.bn.br/hemeroteca-digital/.

CEARENSE. Instrução Pública. Fortaleza. 15 de novembro de 1881.

Disponível em: http://bndigital.bn.br/hemeroteca-digital/.

CEARENSE. Instrucção Pública - Relatório do Dr. Amaro Cavalcanti.

Fortaleza. 13 de outubro de 1881, p. 3. Disponível em:

http://bndigital.bn.br/hemeroteca-digital/.

CEARENSE. Instrucção Pública - Relatório do Dr. Amaro Cavalcanti. Fortaleza. 21 de setembro de 1881, p. 3. Disponível em:

http://bndigital.bn.br/hemeroteca-digital/.

CEARENSE. Instrucção Pública - Relatório do Dr. Amaro Cavalcanti.

Fortaleza. 22 de setembro de 1881, p. 3. Disponível em:

http://bndigital.bn.br/hemeroteca-digital/.

CHAMON, Carla Simone. Escolas em reforma, saberes em trânsito: a trajetória de Maria Guilhermina Loureiro de Andrade (1869-1913). Belo Horizonte: Autentica, 2008.

CIRNE, Moacyr. A invenção de Caicó. Mossoró: Editora Sebo Vermelho, 2004.

CONSTITUIÇÃO. Licença. Fortaleza. 17 de agosto de 1876. Disponível em: http://bndigital.bn.br/hemeroteca-digital/.

ENGEL, Magali G., SOUZA, Flávia F. de; GUERELLUS, Natália de S. (org.). Os intelectuais e a imprensa. Rio de Janeiro: Mauad X: Faperj, 2015.

FERNANDES, Ana Carla Sabino. A imprensa em pauta: entre as contendas e paixões partidárias dos jornais Cearense, Pedro II e Constituição na segunda metade do século XIX. 2004. 206 f. Dissertação (Mestrado em História Social) 
- Programa de Pós-Graduação em História, Universidade Federal do Ceará/UFC, Fortaleza/CE, 2004.

FOUCAULT, Michel. A ordem do discurso. 6. ed., São Paulo: Ed. Loyola, 2000.

GONDRA, José Gonçalves. Instrução, intelectualidade e Império: apontamentos a partir do caso brasileiro. Disponível em:

www.portal.fae.ufmg.br/pensareducacao/arquivos/downloads/.../conf_gondra. pdf. Acesso em: 02 abr. 2017.

IHGB. Amaro Cavalcanti. Instituto Histórico e Geográfico Brasileiro. Disponível em: https://ihgb.org.br/perfil/userprofile/acavalcanti.html. Acesso em: 10 fev. 2017.

MADEIRA, Maria das Graças de Loiola. A instrução pública e o ideário liberal cristão: notas de João Brígido no periódico "O Cearense" - Fortaleza (anos 60 do século XIX). In: CONGRESSO BRASILEIRO DE HISTÓRIA DA EDUCAÇÃO, 2., 2002, Natal/RN. Anais [...] Natal: Sociedade Brasileira de História da Educação/SBHE, 2002.

MIGNOT, Ana Chrystina Venancio; SILVA, Alexandra Lima da. Tão longe, tão perto: escrita de si em relatórios de viagens. Educação em Revista, Belo Horizonte, v. 27, n. 1, p. 435-458, abr. 2011.

NOVAES, Adauto (org.). O silêncio dos intelectuais. São Paulo: Companhia das Letras, 2006.

PALLARES-BURKE, Maria Lúcia G. Gilberto Freyre: um vitoriano dos trópicos. São Paulo: Editora Unesp, 2005.

PEDRO II. Consórcio. Fortaleza, 10 de novembro de 1881. Disponível em: http://bndigital.bn.br/hemeroteca-digital/.

PINTO, Inára de Almeida Garcia. Um professor em dois mundos: a viagem do professor Luiz Augusto dos Reis à Europa (1891). 2011. Tese (Doutorado em Educação) - Programa de Pós-Graduação da Faculdade de Educação, Universidade de São Paulo/USP, São Paulo/SP, 2011.

SCHUELER, Alessandra Frota Martinez de; GONDRA, José Gonçalves. Olhar o outro, ver a si: um professor primário brasileiro no "Velho Mundo" (18901892). Revista Brasileira de História da Educação, n. 22, p. 87-112, 2010. SIMÕES JÚNIOR, Álvaro S.; CAIRO, Luiz Roberto; RAPUCCI, Cleide A. (org.). Intelectuais e imprensa: aspectos de uma complexa relação. São Paulo: 
Nankin, 2009.

SIRINELLI, Jean-François. Os intelectuais. In: RÉMOND, René. Por uma história política. Tradução Dora Rocha. 2. ed. Rio de Janeiro: Editora FGV, 2003.

WOLFF, Francis. Dilemas dos intelectuais. In: NOVAES, Adauto (org.). 0 silêncio dos intelectuais. São Paulo: Companhia das Letras, 2006.

FABIANA SENA é professora associada no Departamento de Metodologia da Educação, do Centro de Educação, e credenciada no Programa de PósGraduação em Educação da Universidade Federal da Paraíba (UFPB), em João Pessoa/PB.

E-mail: fabianasena@yahoo.com.br

(ib) http://orcid.org/0000-0002-3340-7769

Recebido em: 26 de abril de 2018

Aprovado em: 08 de janeiro de 2019

Associação Sul-Rio-Grandense de Pesquisadores em História da Educação - Asphe

Artigo de acesso aberto distribuído nos termos de licença Creative Commons. 